\title{
ANÁLISE SOBRE A EFICÁCIA E APLICABILIDADE DA COLABORAÇÃO PREMIADA $^{1}$
}

ANALYSIS ON THE EFFECTIVENESS AND APPLICABILITY OF AWARDED COLLABORATION

Teresa Cristina de Lima VILLARROEL ${ }^{2}$

Clóvis Alberto VOLPE FILHO

ISSUE DOI: 10.21207/2675-0104.2019.918

\section{RESUMO}

O presente artigo realiza uma análise a respeito da Colaboração premiada de maneira bastante ampla, tendo início por meio do direito comparado entre o sistema brasileiro e institutos correlatos de outros países, em diferentes períodos. Posteriormente foi realizado um estudo das legislaçẽos do Brasil que possuem espécies de colaboração. Tendo esse material reunido, foi possível realizar um estudo mais detalhado a respeito da Lei $\mathrm{n}^{\circ} 12.850 / 13$, Lei de combate às organizações criminosas, no que se refere às inovações relativas à colaboração premiada.

Palavras-chave: Colaboração Premiada. Direito premial. Direito comparado. Evolução legislativa. Análise crítica.

\footnotetext{
${ }^{1} \mathrm{O}$ presente artigo sintetiza a monografia de conclusão da pesquisa, realizada para o Programa Interno de Bolsas de Iniciação Científica (PIBIC 2018-2019) da Faculdade de Direito de Franca (FDF), Franca/SP.

${ }^{2}$ Discente da Faculdade de Direito de Franca (FDF), Franca/SP. Bolsista do Programa Interno de Bolsas de Iniciação Científica (PIBIC 2018-2019).

${ }^{3}$ Possui graduação em Direito pela Faculdade de Direito de Franca (2003), mestrado em Direito Constitucional pela Universidade de Franca (2005), especialização em Ciências Criminais pela PucMinas (2011) e MBA em Direito Empresarial pela FGV (2011). É doutor em Direito Constitucional pela Fadisp, advogado e professor da graduação da Fafram/Ituverava e da Faculdade de Direito de Franca. Tem experiência na área de Direito, com ênfase em Direito Constitucional, Direito Penal e Direito Processual Penal. Foi pesquisador/bolsista durante a graduação pela Fapesp, e durante o mestrado pesquisador/bolsista pela Capes.
} 


\section{ABSTRACT}

This article aims to do an analysis about the Brazilian plea bargaining in a broad way, starting with a comparative law between the brazilian system and themes correlates from other countries in different periods. Efter that, a study was elaborated about the laws of Brazil that presented kinds of collaboration. From this, it was possible to study the details about the Law $n^{\circ} 12.850 / 13$, Law of the combat against criminal organizations, more specifically, about the innovation of collaboration, or Brazilian plea bargaining.

Kayworlds: Brazilian plea bargaining. Law of the prize. Comparative law. Legislative development. Critical analysis.

\section{INTRODUÇÃO}

O crime organizado, assim como alguns outros crimes plurissubjetivos, possuem uma complexidade bastante elaborada para que se configurem como tal, e por esse fator, é necessário que o direito desenvolva recursos diferenciados para combatê-los. A Colaboração Premiada se trata de um deles, assim como a ação controlada e a infiltração de agentes, todos presentes na Lei de combate às organizações criminosas, Lei $n^{\circ} 12.850 / 13$.

A fim de que se pudesse abordar o instituto de forma mais ampla, foi realizada uma investigação no sentido de buscar situações no estrangeiro em que institutos correlatos foram utilizados a fim de coibir diferentes tipos de crime. Abordou-se temas do direito premial da Itália, dos Estados Unidos, da Alemanha, e de Portugal, já que estes foram países que tiveram uma expressão relevante no direito negocial criminal e através disso, se realizou um estudo comparativo bastante interessante com as disposições do Brasil sobre o assunto. Além disso, também foi abordado a Convenção de Palermo, já que este se apresenta como um importante marco internacional contra organizações criminosas.

Posteriormente, foi realizada uma análise da legislação pátria que tivesse relação com a colaboração premiada, já que existem diversas espécies de acordos em leis com diferentes enfoques, que foram instituídas desde o período em que o Brasil era uma colônia, até os dias atuais. Desta forma foi possível acompanhar uma visível evolução legislativa, já que a cada lei posterior, o direito premial se tornava mais elaborado e com mais bases para que a sua implementação fosse de fato realizada.

A política pátria se encontra em um momento delicado atualmente, e por esse motivo a colaboração premiada se coloca em evidência pela frequência de sua utilização frente aos esquemas de corrupção apurados nos últimos anos. Por esse motivo, se faz necessário 
averiguar como o instituto é empregado e levantar questionamentos a respeito deste, já que este é um tema que recebe duras críticas por uns, e ao mesmo tempo, é bastante enaltecido por outros.

Após compilar todas essas informações, a fim de que se possa adquirir um conhecimento mais específico a respeito da lei que atualmente está sendo bastante utilizada no combate à corrupção, e tem potencial para apurar diversos outros crimes praticados no país, o presente artigo busca realizar uma análise mais detalhada sobre cada um dos novos dispositivos que a Lei 12.850/13 proporcionou para a melhor utilização do instituto.

\section{ORIGEM E CONTEXTO HISTÓRICO DA COLABORAÇÃO PREMIADA}

Inicialmente, é importante ressaltar que o termo "Colaboração Premiada" no presente estudo será utilizado como sinônimo de "Delação Premiada" da mesma forma que muitos autores tratam. Porém, parte da doutrina considera que só se pode falar em "delação" quando o agente assume a autoria do crime, aponta outros membros da organização criminosa. Já a respeito da Colaboração, o agente pode negociar informações diversas além da delação, como a respeito da localização e recuperação dos ativos, ou facilitação da libertação da vítima. ${ }^{4}$

Além disso, é importante também se atentar à diferença entre a colaboração e a confissão, já que aquela possui uma estrutura consideravelmente mais complexa, pois se trata de um acordo realizado entre o investigado ou réu, e o Poder Público, possuindo alguns objetivos a serem alcançados para que o correspondente benefício possa ser aplicado. Já a confissão pode fazer com que a pena do agente seja diminuída, porém de forma mais simples. ${ }^{5}$

Dando início à análise de direito comparado pela Itália, é interessante notar que os primeiros institutos de direito premial não tinham como objetivo coibir a Máfia, pois em 1974, com a Lei $\mathrm{n}^{\circ} 497$, foi estabelecido a respeito da extorsão mediante sequestro, que a pena poderia ser diminuída caso o agente ajudasse a vítima a readquirir a liberdade sem o pagamento do resgate, em seus artigos 5 e 6 . Da mesma forma,

\footnotetext{
${ }^{4}$ LIMA, Renato Brasileiro. Manual de processo penal: volume único I - 5. ed. revisada, ampliada e atualizada - Salvador: Ed. JusPodivm, 2017. p. 783.

${ }^{5}$ Id., Ibid. p. $782-783$.
} 
posteriormente ocorreu com relação ao crime de eversão ou de finalidade de terrorismo, pois foram estabelecidos possíveis benefícios aos que auxiliassem a polícia e o judiciário com determinadas informações, e alguns anos depois a dissociação também se tornou uma forma de colaborar 6

Apenas em 1982, foi criado o tipo penal de associação mafiosa, e a partir disso, algumas leis foram criadas a fim de combater tal prática delitiva, aumentando sua pena, criando formas processuais mais eficientes para a situação, e finalmente, oferecendo benefícios para os mafiosos colaboradores. Tais medidas foram bastante utilizadas, e tiveram uma forte repercussão no país, o que neste caso pode ser considerada uma estratégia positiva para o combate à uma modalidade criminosa tão grave. ${ }^{7}$

Com relação aos Estados Unidos, é extremamente importante notar que o sistema utilizado, o common law, é bastante diferente do brasileiro, o civil law, o que faz com que as decisões sejam baseadas em jurisprudências anteriores, atribuindo mais flexibilidade para o aplicador da lei. Em 1970 a Suprema Corte admitiu a negociação de uma espécie de confissão denominada plea bargaining, por facilitar a função do estado, por um benefício na pena, situação de poderias se configurar de duas formas. $^{8}$

Caso o acusado apenas realize a confissão de maneira voluntária, se configura o implicit plea bargaining, já se fosse estabelecido um acordo anterior, seria o explicit plea bargaining. Nessa modalidade há três possibilidades, a sentence bargain, em que a declaração de culpa diminui a pena, a charge bargain, em que é imputado um crime menos gravoso àquele que confessa, e a terceira situação une os dois benefícios. ${ }^{9}$

A respeito da Alemanha, o legislador atribuiu muita liberdade ao magistrado para que esse julgasse o caso concreto de acordo com cada situação específica. Não foi estabelecido um quantum de benefício pela delação, o que será decidido pelo judiciário dependendo de quão proveitosa

\footnotetext{
${ }^{6}$ BITTAR, Walter Barbosa. Delação premiada no Brasil e na Itália. Uma análise comparativa. Revista Brasileira de Ciências Criminais, São Paulo, v. 19, n. 88, p. 225-270., jan./fev. 2011. Disponível em: <http://201.23.85.222/biblioteca/index.asp?codigo_sophia=85535>. Acesso em: 04 nov. 2017. p. $228-231$.

${ }^{7}$ Id., Ibid. p. 231 - 233.

${ }^{8}$ BITTAR, Walter Barbosa; PEREIRA, Alexandre Hagiwara. Breve análise do direito estrangeiro. In: BITTAR, Walter Barbosa. Delação premiada: direito estrangeiro, doutrina, jurisprudência. Rio de Janeiro: Lumen Juris, 2011. Disponível em: <http://201.23.85.222/biblioteca/index.asp?codigo_sophia=86372>. Acesso em: 18 nov. 2017. p. 7-30. Disponível em: <http://201.23.85.222/biblioteca/index.asp?codigo_sophia=86390 >. Acesso em: 04 nov. 2017. p. $25-28$.

${ }^{9}$ Id., Ibid. p. 28 - 29.
} 
aquela for. Em contrapartida, apesar de toda essa liberdade, o juiz deve motivar a decisão de maneira extremamente detalhada. ${ }^{10}$

Ocorreram algumas discussões sobre a legitimidade da colaboração, porém, o Estado Alemão optou por mantê-lo no ordenamento por se tratar de uma forma de obter provas muito eficiente, sem a qual dificilmente tais informações chegariam ao judiciário. Além disso, para que seja aplicada há alguns dispositivos a respeito da proteção e de defesa sobre os envolvidos, e para que seja admitida, é necessário que seja muito consistente e coerente com todo o conjunto probatório do processo. ${ }^{11}$

No Código Penal Português, se faz presente a colaboração premiada tanto no crime de associação ou organização criminosa, quanto no de organizações terroristas, fazendo com que o agente possa ter a sua pena atenuada, ou até mesmo não aplicada, caso impeça que os grupos continuem atuando, ou comunique a autoridade correspondente, evitando a ação criminosa. O assunto é tratado nos artigos $299^{\circ}$ a $301^{\circ}$ do código mencionado. $^{12}$

A Convenção de Palermo é um instrumento de cooperação jurídica internacional que objetiva fazer com que determinadas técnicas especiais de investigação sejam possíveis entre diferentes países, uniformizando determinados institutos, e aproximando os procedimentos das autoridades competentes. É algo extremamente necessário, visto que muitos crimes desta natureza não são cometidos dentro do espaço físico de um mesmo país. ${ }^{13}$

\footnotetext{
${ }^{10}$ PEST, Robert. A colaboração premiada no processo penal alemão. Direito Público, São Paulo, v. 13, n. 74, p. 30-51., mar./abr. 2017. Disponível em: $<$ http://201.23.85.222/biblioteca/index.asp?codigo_sophia=134946>. Acesso em: 04 nov. 2017. p. 4446.

${ }^{11}$ Id., Ibid. p. 47 - 50.

${ }^{12}$ MOSSIN, HeráclitoAntônio; MOSSIN, Júlio César O. G. Delaçãopremiada: Aspectos jurídicos. 3. ed.capítulo 2, 2.1. São Paulo: Jhmizuno, 2016.

${ }^{13}$ GOMES, Rodrigo Carneiro. A investigação criminal na luta contra o crime organizado - aspectos da Convenção de Palermo. Revista Criminal: ensaios sobre a atividade policial, São Paulo, v. 2, n. 5, p. 39-77., $\quad$ out./dez. 2008. Disponível em: <http://201.23.85.222/biblioteca/index.asp?codigo_sophia=86532>. Acesso em: 13 dez. 2017. p. 39 46.
} 


\section{COLABORAÇÃO PREMIADA NO BRASIL: EVOLUÇÃO LEGISLATIVA ATÉ OS DIAS ATUAIS E APLICAÇÃO}

Pode-se elencar três regras que deveriam ser seguidas em acordos de Colaboração. a Primeira é no sentido de agir com cautela, sem desconsiderar a palavra do colaborador, mas verificando a coerência e as possíveis motivações, a segunda se trata da necessidade de corroboração, já que a colaboração deve estar de acordo com as demais provas, e a terceira é sobre a tentativa de utilizar o instituto com membros que estejam hierarquicamente em uma posição base da organização, para que se possa então beneficiá-lo, alcançando então os chefes ou líderes. ${ }^{14}$

O primeiro momento em que o direito premial se fez presente no nosso país, foi com as Ordenações Filipinas, uma legislação estrangeira que foi adotada pelo Brasil quando este era uma colônia de Portugal. Foi por meio desta legislação, que possuia o crime de lesa-magestade e uma forma de direito premial àquele que o delatasse, que Tiradentes foi executado, já que juntamente com Silvério dos Reis compunha o movimento que culminaria na Inconfidência Mineira. Porém, este, a fim de ter suas dívidas pessoais perdoadas, objetivo que atingiu com sucesso, delatou o movimento. ${ }^{15}$

A primeira situação em que de fato o ordenamento jurídico brasileiro apresentou uma espécie de direito premial foi na Lei de Crimes Hediondos, Lei $\mathrm{n}^{\circ} 8.072 / 90$, em seu artigo $8^{\circ}$, parágrafo único, reduzindo a pena daquele que denunciasse o grupo, possibilitando 0 seu desmantelamento. ${ }^{16}$ Além disso, tal alteração teve importante repercussão no Código Penal, por levá-lo a ser alterado em seu artigo 159, referente à extorsão mediante sequestro, caso fosse realizado em concurso,

\footnotetext{
${ }^{14}$ MENDONÇA, Andrey Borges de. A Colaboração premiada e a nova Lei do Crime Organizado (Lei 12.850/2013). Custos Legis a revista eletrônica do Ministério Público Federal vol.4 , [S. 1.], 8 jun. 2016. Disponível em: https://revistacustoslegis.wordpress.com/2016/06/08/a-colaboracao-premiada-ea-nova-lei-do-crimeorganizado-lei-12-8502013/. Acesso em: 7 jul. 2019. p. 12.

15 ALVES FERREIRA, Regina Cirino . HISTÓRIA - CASO TIRADENTES E REPRESSÃo PENAL: PASSADO E PRESENTE. Liberdades revista eletrônica IBCCRIM, [S.1.], v. 1, p. 79-90, maio. 2009.2 Disponível em: <http://www.revistaliberdades.org.br/site/outrasEdicoes/outrasEdicoesExibir.php?rcon_id=11>. Acesso em: 09 nov. 2017.

${ }^{16}$ VASCONCELLOS, Vinícius Gomes de; REIS, Erica do Vale. Justiça criminal premial: introdução à regulamentação jurídica da delação premiada no ordenamento brasileiro e às alterações da lei $\mathrm{n}^{\circ}$ 12.850/2013. Revista Magister de Direito Penal e Processual Penal, Porto Alegre, v. 11, n. 62, p. 3149., out./nov. 2014. Disponível em: <http://201.23.85.222/biblioteca/index.asp?codigo_sophia=111464>. Acesso em: 09 nov. 2017. p.3334.
} 
possibilitando o benefício àquele que denunciasse e facilitasse a libertação da vítima. ${ }^{17}$

Em seguida, a Lei dos crimes contra o sistema financeiro nacional, Lei $\mathrm{n}^{\circ} 7.492 / 86$ foi alterada pela lei $\mathrm{n}^{\circ} 9.080 / 95$, no sentido de possibilitar a bonificação na pena caso o co-autor ou partícipe revelasse toda a trama delituosa às autoridades. A mesma lei alterou da mesma forma a Lei dos crimes contra a ordem tributária, econômica e relações de consumo, Lei $\mathrm{n}^{\circ} 8.137 / 90 .^{18}$

Já a Lei de proteção à vítimas e testemunhas, Lei nº 9.807/99, veio tratar o tema de forma metalinguística, já que estabelece medidas protetivas ao réu colaborador, além de elencar requisitos para determinados tipos de benefícios. ${ }^{19}$

Posteriormente, a Lei de entorpecentes, Lei $\mathrm{n}^{\mathrm{o}} 11.343 / 06$ determinou que aquele que colaborasse na identificação dos demais coautores ou na recuperação total ou parcial do produto do crime, poderia ter a sua pena reduzida. ${ }^{20}$

O Acordo de Leniência, regido pela Lei n ${ }^{\circ} 12.529 / 11$ não se trata de uma espécie de colaboração propriamente dita, porém possui algumas semelhanças que não podem ser ignoradas, já que se trata de um acordo que pode ser firmado com pessoas físicas ou jurídicas, e esta lei estabelece os deveres, sanções, limites e requisitos do acordo. ${ }^{21}$

Em 2012, a Lei no 12.683/12 deu nova redação à Lei de lavagem de capitais, Lei $n^{\circ} 9.613 / 98$, trazendo uma grande evolução para o direito premial, já que a colaboração se apresenta de forma mais ampla, apresentando mais objetivos que o colaborador pode alcançar por meio das informações, e benefícios mais diversos, já que se torna possível a redução

\footnotetext{
${ }^{17}$ BRASIL. Lei n. 9269, de 02 de abr. de 1996. nova redação ao $\S 4^{\circ}$ do art. 159 do Código Penal.. nova redação ao $\S 4^{\circ}$ do art. 159 do Código Penal.. Brasília, p. 1-1, abr. 1996. Disponível em: <http://www.planalto.gov.br/ccivil_03/leis/L9269.htm>. Acesso em: 16 nov. 2017.

${ }^{18}$ BRASIL. Lei n. 9.080, de 19 de jul. de 1995. Acrescenta dispositivos às Leis ${ }^{\circ} \mathrm{s} 7.492$, de 16 de junho de 1986, e 8.137, de 27 de dezembro de 1990. Brasília, jul. 1995. Disponível em: <http://www.planalto.gov.br/ccivil_03/leis/L9080.htm>. Acesso em: 16 nov. 2017.

${ }^{19}$ BRASIL. Lei n. 9.807, de 20 de nov. de 2017. DA PROTEÇÃO ESPECIAL A VÍTIMAS E A TESTEMUNHAS. DA PROTEÇÃO AOS RÉUS COLABORADORES. Brasília, p. 1-1, jul. 1999. Disponível em: <http://www.planalto.gov.br/ccivil_03/leis/L9807.htm>. Acesso em: 16 nov. 2017.

${ }^{20}$ BRASIL. Lei n. 11.343, de 23 de ago. de 2006. Lei de entorpecentes. Lei de drogas. Brasília, ago. 2006. Disponível em: <http://www.planalto.gov.br/ccivil_03/_ato2004-2006/2006/lei/111343.htm>. Acesso em: 17 nov. 2017.

${ }^{21}$ BRASIL. Lei n. 12.529, de 30 de nov. de 2011. Estrutura o Sistema Brasileiro de Defesa da Concorrência; dispõe sobre a prevenção e repressão às infrações contra a ordem econômica;[...] Brasília, nov. de 2011. Disponível em: http://www.planalto.gov.br/ccivil 03/ ato20112014/2011/Lei/L12529.htm Acesso em 2 de nov. de 2017.
} 
da pena, a troca de regime inicial, a substituição da prisão por uma pena restritiva de direitos ou até mesmo o perdão judicial. ${ }^{22}$

Por fim, a Lei de combate às organizações criminosas, Lei $\mathrm{n}^{\circ}$ $12.850 / 13$, tornou o instituto muito mais prático que anteriormente, poi não havia especificações de como deveria ser aplicado, quais as responsabilidades, qual o trâmite que o acordo deve percorrer, requisitos e demais pontos relevantes, sem os quais a aplicação se encontrava dificultada. Tal legislação proporcionou uma eficácia muito maior à colaboração, já que a partir dela, todos os envolvidos no acordo teriam maior suporte. ${ }^{23}$

A partir de uma análise jurisprudencial, é possível notar que apesar de nos grandes casos midiáticos o instituto se apresentar de forma bastante frequente e geralmente alcançar os objetivos, nos casos menores não ocorre o mesmo, já que muitas vezes o acordo não surte os efeitos desejados pelas partes por diversos motivos.

Por outro lado, com relação ao caso da Lava Jato, é evidente que os prêmios obtidos pelos grandes acordos realizados foram exorbitantes, frente aos crimes cometidos e os valores atribuídos a estes, como o referente ao do Paulo Roberto Costa e de Alberto Youssef, casos que repercutiram de maneira bastante intensa pela quantidade de benefício obtidos. Porém, por outro lado, grandes esquemas de corrupção foram descobertos por meio dessas colaborações, o que muito provavelmente não seria possível sem estas.

\section{A COLABORAÇÃO PREMIADA NA LEI 12.850/2013, LEI DE COMBATE ÀS ORGANIZAÇÕES CRIMINOSAS}

Para possibilitar que uma melhor compreensão do desenvolvimento do instituto, é necessário um estudo abordando as questões que anteriormente não eram tratadas pelos textos legais. Com a elaboração da legislação específica sobre o assunto muitas lacunas foram preenchidas, determinando os procedimentos que esta deve seguir e novas

\footnotetext{
${ }^{22}$ BRASIL. Lei n. 12.683, de 03 de mar. de 1998. Eficiência à persecução penal dos crimes de lavagem de dinheiro.. lavagem de dinheiro. Brasília, mar. 1998. Disponível em: <http://www.planalto.gov.br/ccivil_03/_ato2011-2014/2012/lei/112683.htm>. Acesso em: 22 nov. 2017.

${ }^{23}$ NUCCI, Guilherme de Souza. Organização Criminosa : - Comentários À Lei 12.850, de 02 de Agosto de 2013. $3^{\circ}$ edição. ed. São Paulo: Revista dos Tribunais, 2015.
} 
possibilidades que esta pode apresentar, possibilitando, portanto, a sua aplicação de forma mais adequada.

A Colaboração premiada é um assunto bastante conflituoso do ordenamento jurídico, porém, uma forma interessante de lidar com a problemática é fazendo com que aqueles que estão envolvidos em suas etapas se comprometam a realizar suas funções da maneira mais ética possível, o que inclui proporcionar maior conhecimento e maior segurança ao possível colaborador.

De acordo com Vicente Greco Filho, o acordo de colaboração premiada deve passar por três fases. A primeira trata-se do momento de negociação, dos quais se trata o artigo $4^{\circ}, \S 6^{\circ}$ e $\$ 7^{\circ}$, e o artigo $6^{\circ}$ da Lei 12.850 , o acordo até este momento é apenas uma proposta que não vincula o juiz da sentença, já que não há a participação deste, pois os polos das tratativas são apenas a autoridade policial, com a manifestação do Ministério Público e o investigado juntamente com seu defensor, ou o Ministério público e o acusado, igualmente acompanhado pelo seu defensor. Já a segunda fase, o juiz passa a participar pois é a fase de homologação, regida pelo artigo $4^{\circ}$, novamente o $\$ 7^{\circ}$ e $\$ 8^{\circ}$ e o artigo $7^{\circ}$, que abordam requisitos legais e de voluntariedade que o juiz deve verificar para a homologação, além da distribuição sigilosa do pedido. Esta fase se conclui com uma decisão interlocutória que qualifica o colaborador como tal. A terceira fase se dá com a sentença que decide o mérito da questão, concedendo o benefício ao colaborador na medida da utilidade da sua colaboração. Esta fase está descrita no artigo $4^{\circ}, \S 1^{\circ}, \S 8^{\circ}$ segunda parte, $\S 11^{\circ}$ e levando em conta o $\$ 16^{25}$

Importante notar que o $\S 3^{\circ}$ quando aborda a suspensão do prazo de oferecimento de denúncia ou o processo, e do prazo prescricional, não se trata de um prêmio, e sim, uma medida de apoio para que a Justiça possa realizar as medidas cabíveis referentes à colaboração. O melhor entendimento sobre o assunto compreende que tal fator não ocorre automaticamente, devendo haver um requerimento do Ministério Público em juízo nesse sentido, já quem nem sempre a suspensão será necessária. Com relação à possibilidade do magistrado discordar do pedido, deve-se

\footnotetext{
${ }^{24}$ VASCONCELLOS, Vinícius Gomes de; SOUSA, Matheus Herren Falivene de. Código de ética da advocacia na justiça criminal negocial: proposta de regras deontológicas para integridade defensiva na colaboração premiada. Boletim IBCCRIM, São Paulo, v. 26, n. 303, p. 13-15., fev. 2018. Disponível em: 〈http://201.23.85.222/biblioteca/index.asp?codigo_sophia=140245>. Acesso em: 09 abr. 2019. p. 13-14.V

${ }^{25}$ GRECO FILHO, Vicente. Comentários à lei de organização criminosa: Lei n. 12.850/2013. Seção I. 1 ed. São Paulo. Saraiva. 2014. ISBN: Digital: 9788502217799
} 
aplicar por analogia o artigo 28 do Código de Processo Penal, situação em que será acionado o Procurador-Geral de Justiça. ${ }^{26}$

Outra questão bastante discutida a respeito da nova legislação é a respeito do artigo $4^{\circ}, \S 14$, que determina que o colaborador renunciará ao direito ao silêncio, passando a concordar com o compromisso de dizer a verdade. A questão criticada não é pontuada apenas sobre o conflito principiológico, e sim a respeito da redação. Uns apontam como absurdo a legislação impor a renúncia a um direito, quando na realidade este apenas pode ser renunciado de forma voluntária e espontânea. ${ }^{27}$

Por outro lado, há quem defenda que a escrita foi equivocada pelo fato de se tratar de um direito fundamental, e portanto irrenunciável, de acordo com a Constituição Federal, "Art. $5^{\circ}$, LXIII - o preso será informado de seus direitos, entre os quais o de permanecer calado, sendo-lhe assegurada a assistência da família e de advogado;" e a Convenção Americana sobre Direitos Humanos, Art. $8^{\circ}, \S 2^{\circ}, \mathrm{g}^{28}$. Por esse motivo, trata-se de um direito que o agente possui a liberdade de exercê-lo ou não, dependendo de seus interesses e da situação concreta que o possível colaborador se encontra. Esta tese pode ser confirmada pelo artigo $4^{\circ}, \S 10$, já que possibilita a retratação. ${ }^{29}$

Sobre a retratação, as partes a qual a lei se refere que podem retratar-se são Ministério Público e o investigado ou réu, pois o delegado de polícia não é parte propriamente dita do acordo. Não é necessário que haja uma finalidade ou motivação específica para tanto, nem apreciação judicial, se ocorrer antes da homologação, respeitando apenas a vontade das partes. Com relação ao momento adequado para acorrer, a lei é omissa, e a doutrina diverge em quatro posicionamentos diferentes. ${ }^{30}$

A primeira compreende que pela legislação tratar da retratação da proposta e não do acordo, esta seria possível até o momento da assinatura do acordo. A segunda considera que o momento adequado é

\footnotetext{
${ }^{26}$ MASSON, Cleber. MARÇAL, Vinícius. Crime organizado. 2 ed. revisada, atualizada e ampliada. Rio de Janeiro. Forense. São Paulo: Método, 2016. p. 153-156.

${ }^{27}$ MOREIRA, Rômulo de Andrade. A nova lei de organização criminosa: Lei n. 12.850/2013. Revista Magister de Direito Penal e Processual Penal, Porto Alegre, v. 10, n. 55, p. 42-56., ago./set. 2013. Disponível em: http://201.23.85.222/biblioteca/index.asp?codigo_sophia=102425. Acesso em: 20 de agosto de 2019. p. 51.

${ }^{28}$ Toda pessoa acusada de delito tem direito a que se presuma sua inocência enquanto não se comprove legalmente sua culpa. Durante o processo, toda pessoa tem direito, em plena igualdade, às seguintes garantias mínimas: g. direito de não ser obrigado a depor contra si mesma, nem a declarar-se culpada; ${ }^{29}$ BRASILEIRO DE LIMA. Renato. Manual de processo penal: volume único I- 5. ed. rev .. ampl. e atual.- Salvador: Ed. JusPodivm, 2017. pág. 785.

${ }^{30}$ MASSON, Cleber. MARÇAL, Vinícius. Crime organizado. 2 ed. revisada, atualizada e ampliada. Rio de Janeiro. Forense. São Paulo: Método, 2016. p.180 - 182.
} 
entre a homologação e a sentença penal condenatória. Já a terceira, interpreta que deve ocorrer antes da homologação, pois após esse momento, torna-se acervo probatório. A quarta corrente defende que até a homologação pode haver a retratação pela vontade de apenas uma das partes. Após a homologação, até o momento da sentença, pode haver a retratação, porém, para evitar a má fé e deslealdade processual, o distrato que será chancelado em juízo, deve ser subscrito por ambas as partes. ${ }^{31}$

A respeito da publicidade do acordo, no artigo $7^{\circ}, \S 2^{\circ}$ e $3^{\circ}$ é determinado que é sigiloso até o recebimento da denúncia, tendo acesso restrito ao juiz, Ministério Público, Delegado de Polícia, e ao Defensor aos elementos de prova que digam respeito ao exercício do direito de defesa. Porém, antes mesmo deste regramento, havia o posicionamento de que deveria haver um sigilo absoluto do acordo, devendo haver a publicidade apenas no caso de o colaborador ser ouvido no processo de outro coautor delatado. Outro posicionamento existente é no sentido contrário ao sigilo do acordo, por infringir o princípio da publicidade do processo. ${ }^{32}$

O entendimento jurisprudencial, de acordo com o julgamento da Primeira Turma do STF ao HC 90.688/PR, o sigilo do acordo é necessário, e deve ocorrer em proteção à integridade física não só do colaborador, mas de sua família também. ${ }^{33}$

$\mathrm{O}$ artigo $5^{\circ}$ da Lei 12.850/13 elenca os direitos do colaborador, uma inovação bastante positiva visto que sem estas a aplicação do instituto se encontrava bastante dificultada, pois o colaborador se coloca em uma situação de vulnerabilidade bastante considerável por fornecer à justiça informações relativas à uma organização criminosa, e possivelmente seus membros, o que torna a situação mais delicada.

$\mathrm{O}$ inciso I se refere à Lei de proteção à vítimas e testemunhas, Lei $\mathrm{n}^{\circ}$ 9.807/99, o que faz com que os colaboradores possam ser contemplados com as medidas do programa especial da que esta lei trata, principalmente em seu artigo $7^{\circ}$. As medidas de proteção podem alcançar não somente o colaborador, mas também sua família, caso seja necessário. Estas medidas, quando necessárias, serão aplicadas após a homologação do acordo. ${ }^{34}$

\footnotetext{
${ }^{31}$ Id., Ibid. p. 181.

32 MARQUES, Antonio Sergio Peixoto. A colaboração premiada: um braço da justiça penal negociada. Revista Magister de Direito Penal e Processual Penal, Porto Alegre, v. 10, n. 60, p. 32-66., jun./jul. 2014. Disponível em: http://201.23.85.222/biblioteca/index.asp?codigo_sophia=106451. Acesso em: 15 de ago. 2019. p. 56.

${ }^{33}$ Id., Ibid. p. 56.

${ }^{34}$ GRECO FILHO, Vicente. Comentários à lei de organização criminosa: Lei n. 12.850/2013. Seção I. 1 ed. São Paulo. Saraiva. 2014. ISBN: Digital: 9788502217799
} 
Uma questão interessante que a legislação específica trouxe ao instituto estudado, foi a possibilidade de que este ocorra após a sentença, em seu artigo $4^{\circ}, \S 5^{\circ}$. A Lei de lavagem de capitais já previa em seu artigo $1^{\circ}, \S 5^{\circ}$ que a colaboração poderia ocorrer "a qualquer tempo", porém em um crime muito específico, além do termo abrir a possibilidade de diversas interpretações. É importante salientar que o juízo competente na fase posterior à sentença recorrível é o tribunal correspondente, já na colaboração tardia, ou seja aquela que é feita após o trânsito em julgado, será definido por distribuição autônoma. ${ }^{35}$

\section{$5 \quad$ CONCLUSÃO}

O presente artigo teve como objetivo realizar uma análise da evolução do instituto da Colaboração Premiada, por meio de um estudo a respeito de legislações estrangeiras que trataram do assunto em diferentes situações, e em diferentes períodos da história. Essa abordagem possibilitou uma visão mais abrangente a respeito do tema.

Posteriormente, tendo sido realizada um aprofundamento na própria legislação nacional, várias leis foram elencadas a fim de se compreender como se daria a aplicação da colaboração em cada uma delas, com enfoques diferentes e em alguns casos, apresentando peculiaridades que tornavam a utilização do instituto mais ou menos complexa.

Por fim se chegou à legislação mais complexa e atual que rege a Colaboração Premiada, ou seja, a Lei de combate às organizações criminosas, a Lei $\mathrm{n}^{\mathrm{o}}$ 12.850/13. Esta legislação apresenta um desenvolvimento bastante considerável por determinar mais possibilidades de objetivos para o colaborador e mais benefícios que podem ser oferecidos pelo Ministério Público, por elencar direitos e devere do colaborador, além de sanar várias omissões anteriores a respeito do procedimento processual da colaboração.

Desta forma, se faz necessário o estudo de uma legislação tão mais complexa que as anteriores, pois ainda existem vários questionamentos e divergências doutrinárias a respeito de determinados pontos, porém, apenas por meio do estudo específico é que se pode lapidar tais questões.

\footnotetext{
${ }^{35}$ MASSON, Cleber. MARÇAL, Vinícius. Crime organizado. 2 ed. revisada, atualizada e ampliada. Rio de Janeiro. Forense. São Paulo: Método, 2016. p.173 - 176.
} 
A Lei $n^{\circ} 12.850 / 13$ trouxe a colaboração premiada como um tema muito mais prático e aplicável de acordo com a realidade processual, o que foi de extrema importância para o momento político atual em que o Brasil se encontra, já que nos últimos anos foi um importante instrumento de combate à corrupção.

Pode-se concluir, portanto, que a Colaboração Premiada vem evoluindo de maneira notável, chegando até a legislação atual, porém, isso não significa que ainda possuam questionamentos e críticas relativos a ela, e, portanto, o desenvolvimento é contínuo. O tema deve ser bastante estudado pois, agora que a aplicação se tornou mais frequente e eficiente pela nova lei, o instituto deve ser lapidado.

\section{REFERÊNCIAS BIBLIOGRÁFICAS}

AIRES, Murilo Thomas; FERNANDES, Fernando Andrade. A colaboração premiada como instrumento de política criminal: a tensão em relação às garantias fundamentais do réu colaborador. Revista brasileira de direito processual penal, Belo Horizonte, v. 3, n. 1, p. 253-284., 2017. Disponível em: http://201.23.85.222/biblioteca/index.asp?codigo_sophia=133461. Acesso em: 15 abr. 2019.

BITTAR, Walter Barbosa. Delação premiada no Brasil e na Itália: Uma análise comparativa. Revista Brasileira de Ciências Criminais, São Paulo, v. 19, n. 88, p. 225-270., jan./fev. 2011. Disponível em: http://201.23.85.222/biblioteca/index.asp?codigo_sophia=85535. Acesso em: 04 nov. 2017.

BITTAR, Walter Barbosa; PEREIRA, Alexandre Hagiwara. Breve análise do direito estrangeiro. In: BITTAR, Walter Barbosa. Delação premiada: direito estrangeiro, doutrina, jurisprudência. Rio de Janeiro: Lumen Juris, 2011. Disponível em: http://201.23.85.222/biblioteca/index.asp?codigo_sophia=86372. Acesso em:04 de nov.. 2017. p. 730. Disponível em: http://201.23.85.222/biblioteca/index.asp?codigo_sophia=86390. Acesso em: 04 nov. 2017.

BRASIL. Lei n. 11.343, de 23 de ago. de 2006. Lei de entorpecentes. Lei de drogas. Brasília, p. 1-10, ago. 2006. Disponível em: http://www.planalto.gov.br/ccivil_03/_ato2004-2006/2006/lei/111343.htm. Acesso em: 17 nov. 2017.

BRASIL. Lei n. 12.683, de 03 de mar. de 1998. Eficiência à persecução penal dos crimes de lavagem de dinheiro. Lavagem de dinheiro. Brasília, p. 1-12, mar. 1998. Disponível em:

http://www.planalto.gov.br/ccivil_03/_ato2011-2014/2012/lei/112683.htm. Acesso em: 19 nov. 2017.

BRASIL. Lei n. 12.850, de 02 de ago. de 2013. Organizações criminosas. Delação premiada. Brasília, p. 1-9, ago. 2013. Disponível em: http://www.planalto.gov.br/ccivil_03/_ato2011-

2014/2013/lei/112850.htm. Acesso em: 9 de junho de 2019.

BRASIL. Lei n. 8072, de 25 de jul. de 1990. Crimes hediondos. Brasília, p. 1-4, jul. 1990. Disponível em: http://www.planalto.gov.br/ccivil_03/leis/L8072.htm. Acesso em: 16 nov. 2017. 
BRASIL. Lei n. 9080, de 19 de jul. de 1995. Acrescenta dispositivos às Leis nºs 7.492, de 16 de junho de 1986, e 8.137, de 27 de dezembro de 1990. Brasília, jul. 1995. Disponível em: http://www.planalto.gov.br/ccivil_03/leis/L9080.htm. Acesso em: 16 nov. 2017.

BRASIL. Lei n. 9269, de 02 de abr. de 1996. nova redação ao $§ 4^{\circ}$ do art. 159 do Código Penal. Brasília, abr. 1996. Disponível em: http://www.planalto.gov.br/ccivil_03/leis/L9269.htm. Acesso em: 16 nov. 2017.

BRASIL. Lei n. 9807, de 20 de nov. de 2017. DA PROTEÇÃO ESPECIAL A VÍTIMAS E A TESTEMUNHAS. DA PROTEÇÃO AOS RÉUS COLABORADORES. Brasília, p. 1-1, jul. 1999. Disponível em: http://www.planalto.gov.br/ccivil_03/leis/L9807.htm. Acesso em: 16 nov. 2017.

BRASILEIRO DE LIMA, Renato. Manual de processo penal: volume único. 5. ed. revista ampliada e atualizada- Salvador: Ed. JusPodivm, 2017.

CUNHA, Rogério Sanches. Manual de Direito Penal- Parte geral. Salvador -BA: JusPodivm, 2015.

GOMES, Marielle Figueredo. Delação Premiada à luz dos princípios constitucionais. Disponível em: https://mariellefgomes.jusbrasil.com.br/artigos/496730696/delacao-premiada-a-luz-dos-principiosconstitucionais/ Acesso em: 20 de maio de 2019.

GOMES, Rodrigo Carneiro. A investigação criminal na luta contra o crime organizado - aspectos da Convenção de Palermo. Revista Criminal: ensaios sobre a atividade policial, São Paulo, v. 2, n. 5, p. 39-77., out./dez. 2008. Disponível em:

http://201.23.85.222/biblioteca/index.asp?codigo_sophia=86532. Acesso em: 13 dez. 2017.

GRECO FILHO, Vicente. Comentários à lei de organização criminosa: Lei n. 12.850/2013. Seção I. 1 ed. São Paulo. Saraiva. 2014. ISBN: Digital: 9788502217799

JESUS, Damásio Evangelista de. O prêmio à delação nos crimes hediondos. Boletim IBCCRIM, São Paulo, n. 5, p. 1., jun. 1993. Disponível em:

http://201.23.85.222/biblioteca/index.asp?codigo_sophia=13361. Acesso em: 9 jun. 2019.

LOPES JÚNIOR, Aury; ROSA, Alexandre Moraes. Com delação premiada e pena negociada, Direito Penal também é lavado a jato. Revista Consultor Jurídico, [S. 1.], 24 jul. 2015. Disponível em: https://www.conjur.com.br/2015-jul-24/limite-penal-delacao-premiada-direito-penal-tambem-lavadojato. Acesso em: 15 maio 2019.

MARQUES, Antonio Sergio Peixoto. A colaboração premiada: um braço da justiça penal negociada. Revista Magister de Direito Penal e Processual Penal, Porto Alegre, v. 10, n. 60, p. 32-66., jun./jul. 2014. Disponível em: http://201.23.85.222/biblioteca/index.asp?codigo_sophia=106451. Acesso em: 13 abr. 2019.

MASSON, Cleber; MARÇAL, Vinícius. Crime organizado. 2. ed. Rio de janeiro: Forense; São Paulo: MÉTODO, 2016.

MENDONÇA, Andrey Borges de. A Colaboração premiada e a nova Lei do Crime Organizado (Lei 12.850/2013). Custos Legis a revista eletrônica do Ministério Público Federal vol.4, [S. 1.], 8 jun. 2016. Disponível em:https://revistacustoslegis.wordpress.com/2016/06/08/a-colaboracao-premiada-ea-nova-lei-do crimeorganizado-lei-12-8502013/. Acesso em: 7 jul. 2019. 
MESSA, Ana Flávia ; CARNEIRO, José Reinaldo G. Crime Organizado. 1. ed. São Paulo. Editora Saraiva, 2012. 691 p., $22 \mathrm{~cm}$. ISBN 978-85-02-1151-6. Disponível em:

http://201.23.85.222/biblioteca/index.asp?codigo_sophia=102553.. Acesso em: 10 dez. 2017. ISBN digital: 9788502149977

MINISTÉRIO PÚBLICO FEDERAL. Grandes casos. Lava Jato em números no Paraná. Disponível em: http://www.mpf.mp.br/grandes-casos/caso-lava-jato/atuacao-na-1a-instancia/parana/resultado.

MORAIS, Hermes Duarte. Regime jurídico da colaboração premiada: direitos e deveres das partes e poderes do juiz. 2018. Dissertação (Mestre em ciências jurídicas) - Faculdade de Direito de Ribeirão Preto da Universidade de São Paulo, Ribeirão Preto, 2018.

MOSSIN, Heráclito Antônio; MOSSIN, Júlio César O. G. Delação Premiada: Aspectos jurídicos. 1. ed. São Paulo: Jhmizuno, 2016.

NUCCI, Guilherme de Souza. Organização Criminosa: Comentários À Lei 12.850 de 02 de Agosto de 2013. 3 ed. São Paulo: Revista dos Tribunais, 2015.

O GLOBO. Todas as fases da Operação Lava Jato. Disponível em:

https://infograficos.oglobo.globo.com/brasil/todas-as-fases-da-operacao-lava-jato.html\#58 Acesso em 20 de agosto de 2019.

PEST, Robert. A colaboração premiada no processo penal alemão. Direito Público, São Paulo, v. 13, n. 74, p. 30-51., mar./abr. 2017. Disponível em:

http://201.23.85.222/biblioteca/index.asp?codigo_sophia=134946. Acesso em: 04 nov. 2017.

TEOTÔNIO, Paulo José Freire; SILVA, Bruna Carolina Oliveira e. Delação premiada sob o enfoque da razoabilidade e proporcionalidade. Revista Magister de Direito Penal e Processual Penal, Porto Alegre, v. 12, n. 68, p. 40-64., out./nov. 2015. Disponível em:

http://201.23.85.222/biblioteca/index.asp?codigo_sophia=128799. Acesso em: 25 mai. 2019.

VASCONCELLOS, Vinícius Gomes de; REIS, Erica do Vale. Justiça criminal premial: introdução à regulamentação jurídica da delação premiada no ordenamento brasileiro e às alterações da lei $\mathrm{n}^{\circ}$ 12.850/2013. Revista Magister de Direito Penal e Processual Penal, Porto Alegre, v. 11, n. 62, p. 31 49., out./nov. 2014. Disponível em:

http://201.23.85.222/biblioteca/index.asp?codigo_sophia=111464. Acesso em: 27 de maio de 2017.

VASCONCELLOS, Vinícius Gomes de; SOUSA, Matheus Herren Falivene de. Código de ética da advocacia na justiça criminal negocial: proposta de regras deontológicas para integridade defensiva na colaboração premiada. Boletim IBCCRIM, São Paulo, v. 26, n. 303, p. 13-15., fev. 2018.

Disponível em: http://201.23.85.222/biblioteca/index.asp?codigo_sophia=140245. Acesso em: 09 abr. 2019. 